\title{
Signal Strength Variation and Propagation Profiles of UHF Radio Wave Channel in Ondo State, Nigeria
}

\author{
A. Akinbolati ${ }^{\mathrm{a}^{*}}$, O. Akinsanmi $^{\mathrm{b}}$, K.R. Ekundayo ${ }^{\mathrm{c}}$ \\ $a^{*}, \mathrm{c}$ Department of Physics, Federal University Dutsinma, Katsina State, Nigeria \\ ${ }^{b}$ Department of Electrical and Electronics Engineering, Federal University Oye-Ekiti, Nigeria
}

\begin{abstract}
This study investigated the received signal strength and the propagation profiles for UHF channel 23, broadcast signal in Ondo State, Nigeria, at various elevation levels. The signal strength was measured quantitatively across the state along several routes with the aid of a digital field strength meter. A global positioning system (GPS) receiver was used to determine the elevation above ground level, the geographic coordinates and the line of sight of the various data points from the base station. Data obtained were used to plot the elevation and propagation profiles of the signal along measurement's routes. Results showed that the signal strength was strongest towards the northern parts with respect to distance compared to other routes with the same distance contrary to inverse square law. The threshold signal level for the station was $20 \mathrm{~dB} \mu \mathrm{V}$ which was recorded up to $50 \mathrm{~km}$ line of sight from the transmitter towards the northern parts of the state where higher levels of elevation of data locations were recorded and $42 \mathrm{~km}$ towards the southern parts with lower values of elevation. The propagation profiles for all the routes follow the elevation pattern of the study areas, with some farther locations recording higher signal strength compared to closer locations to the transmitter contrary to theoretical expectation. The overall results show that elevation above ground level is a key factor to be considered for UHF transmission and reception (location of transmitters, transmitting antenna's height, directivity and gain. Others are, transmitter output power, receiving antenna's height and gain) in the study areas.
\end{abstract}

Index Terms: Propagation profiles, signal strength, power density, line of sight, elevation and UHF

(C) 2016 Published by MECS Publisher. Selection and/or peer review under responsibility of the Research Association of Modern Education and Computer Science

\section{Introduction}

Propagation profile is an essential parameter in radio wave propagation theory and equipment design. It is the variation of the electric field strength of a radio signal with distance (Ajayi, G. O., and Owolabi, I. E., 1979).

* Corresponding author.

E-mail address: aakinbolati@fudutsinma.edu.ng, akinsanmi2013@gmail.com, kekundayo@ fudutsinma.edu.ng 
It helps to predict the received signal strength (RSS) (Zeinab, T., et al., 2013) from locations away from the transmitter. It depends on transmitter power, the nature of signal path (rural or urban) and the terrain of the locations involved (Bothias, L., 1987; Kenedy, G., and Bernard, D., 1986). It is used for radio propagation planning and designing (Bothias, L., 1987; CCIR Report 239-6, 1986). Since 1963, the VHF/UHF propagation curves which have been in use for international planning are those published by the (ITU-R). The curves depict the decay of field strength with distance for a range of transmitting antenna heights, the latter being defined in terms of the altitude of the antenna above the mean height of the terrain within the range 3 to $15 \mathrm{~km}$ of the transmitting mast (CCIR Report 239-6, 1986).

Motivation for the research: the international telecommunications union radio (ITU-R) has encouraged scientists and engineers in their respective Countries to carry out researches leading to the development of signal propagation profile/curve in their localities (CCIR Report 239-6, 1986). It was based on this premise that this work was conceived to investigate the received signal strength and the propagation profiles for a UHF broadcast channel in Ondo State, Nigeria. These findings are very important for radio wave propagation and equipment design on the UHF band by radio scientists and engineers. Propagation profiles are also useful at predicting the power received or lost at a given distance from the transmitter which is useful in path loss calculation and modelling. Many published work had shown that path loss modelling plays a key role in coverage area's estimation (Ayeni, A. A., et al., 2015). The tremendous growth of wireless communication system and especially mobile radio system requires radio coverage prediction models and mechanism (Yihuai, Y., et al, 2012). The coverage areas of broadcast stations have a significant influence on the socio-economic life of the citizenry especially in Nigeria (Akinbolati, A., et al, 2015, and Ajewole, M.O., et al., 2014) thus making this work a good feedback mechanism between the communities in the study areas and the government. It also creates a platform for scientific analysis on the behaviour of the UHF signal in different terrains.

\subsection{Electromagnetic Waves}

Electromagnetic waves are transverse waves. The electric and magnetic fields are perpendicular to the direction of propagation. They carry both the electric and magnetic energy of the waves. The electric and the magnetic fields are in phase and mutually perpendicular and their amplitudes are related by

$$
\mathrm{B}_{0}=\frac{\mathrm{k}}{\omega} \mathrm{E}_{0}=\frac{1}{\mathrm{c}} \mathrm{E}_{0}
$$

Where $\mathrm{k}$ is the propagation constant, $\omega$ is the angular frequency of the wave, $\mathrm{c}$ is the speed of light in space and $E_{o}$ is the magnitude of the electric field intensity.

In general for a sinusoidal wave, the variation of the electric field Intensity in space and time is represented as;

$$
E(r, t)=\bar{E}_{0} e^{i(k r-\omega t)} \cdot \hat{n}
$$

and the magnetic field strength

$$
\bar{B}(r, t)=\frac{1}{c} \bar{E}_{0^{i}}{ }^{i}(k \cdot r-\omega t) \cdot(\hat{k} \times \hat{n})
$$

Where $\widehat{k}$ is the propagation vector, $\hat{n}$ is a unit vector in the direction of propagation of the wave- the 
polarization vector, $r$, is the space coordinate

The ratio of the electric field intensity to the magnetic field intensity is defined as

$$
\frac{|E|}{|H|}=\frac{E_{x}}{H_{y}}=\sqrt{\frac{\mu_{0}}{\varepsilon_{0}}}=Z_{0}
$$

Where, $Z_{0}$ is the wave impedance or characteristic impedance of the wave, in free space? $\left(Z_{0}=377 \Omega\right)$

\subsection{Power Density (The Inverse Square Law)}

Power density is defined as the radiated power per unit area (Bothias, L., 1987). It is inversely proportional to the square of the distance from the source and directly proportional to the transmitted power (Bothias, L., 1987; Kenedy, G., and Bernard, D., 1992). That is, if the distance from a transmitter is doubled, the power density of the radiated wave at the new location is reduced to one-quarter of its previous value (Ajewole, M.O., and Oyedum, O. D., et al., 2013). This is the inverse square law, which universally applies to all forms of radiation in free space. Therefore,

$$
\begin{aligned}
& P_{d} \propto \frac{p_{t}}{r^{2}} \\
& P_{d}=\frac{p_{t}}{4 \pi r^{2}}
\end{aligned}
$$

Where, $\mathrm{P}_{\mathbb{Q}}$ is the power density at a distance $\mathrm{r}(\mathrm{m})$, from the transmitter, $P_{\mathrm{t}(\mathrm{W})}$ is the transmitted power.

At distance $r$ from the transmitter, the electric field strength is represented as; (Bothias, L., 1987)

$$
\|E\|=\frac{\sqrt{30 P_{\mathrm{r}}}}{r}
$$

$|E|$ is in Volt/metre, $r$, is in metres and $P_{t}$ is the power transmitted in watts. When the gain of the transmitting antenna is considered, then $|\mathrm{E}|$ becomes:

$$
|E|=\frac{\sqrt{30 P_{t} G_{t}}}{r}
$$

$G_{t}$ is the gain of the transmitting antenna measured in $d B$.

\subsection{Review of Related Work}

Transmission of signal on the UHF broadcast band is by space wave which propagates on line of sight from the transmitter through the troposphere. Thus, the signal received at locations from the transmitter could be the direct transmitted wave, the reflected wave or the diffracted wave (Ajewole, M.O., et al., 2014). This is due to the effect of terrestrial objects on the propagation path (Ajewole, M.O., et al., 2014; Akinbolati, A., et al., 2015). Other factors that determine the quality of signal received from the transmitter on the UHF band include: transmitter output power or the effective isotropic power of the transmitter (EIRP), transmitting antenna height, and the nature of the signal path. Others are transmitter-receiver distance, elevation above ground level of the receiver and the gain of the receiving antenna. (Kenedy, G., and Bernard, D., 1992; Ajewole, M.O., and 
Oyedum, O. D et al., 2013) There is also the attenuation effect on UHF signal caused by precipitation (Ajewole, M.O., and Akinbolati, A., et al., 2014) and foliage (Ayekomilogbon, O. T., et al., 2013). Other factors leading to distorted received signal strength are multipath effects and fading which are caused by atmospheric ducts, ionospheric reflection and refractions (Samridhi, D., and Malhotra, J., et al, 2015). Other causes of multi path and attenuation of radio wave are the existence of physical objects on propagation path, such as trees, buildings and hills as reported in the work of (Samarendra, N. S., and Debjyoti, G., 2013). The work of Armoogun (Armoogun, V., et al, 2010) underscores the importance of path loss prediction and coverage areas in radio and television broadcast system, since the wave interacts with the environment leading to attenuation of signal. The novel results of all these works make propagation curve an essential tool for radio wave propagation planning, designing and loss estimation.

\subsection{Study Areas and the Experimental Station}

Ondo State is one of the states in Nigeria located in the south west geo-political zone of the Country, with Akure as the State Capital. The State has eighteen local government areas and lies between latitude $7^{0} 10^{\prime}$ north and longitude $5^{0}, 05^{\prime}$ east with a landmass of $15,300 \mathrm{~km}^{2}$. It has a population of $3,460,877$ (National Bureau of Statistics, 2010) and a population density of $220 / \mathrm{km}^{2}$. The State is the largest producer of cocoa, and the fifth producer of crude oil in Nigeria. It has three major divisions- Ondo North, Ondo Central and Ondo South. Fig. 1., presents the map of Ondo State whereas, Fig. 2., presents the digital map of the state showing some of the routes where electric field strength measurements were carried out. The experimental station is the UHF channel 23 television station owned by the Ondo State government of Nigeria. It is the station with the highest transmitter power in the State on the UHF band (Ajewole, M.O., et al., 2014).

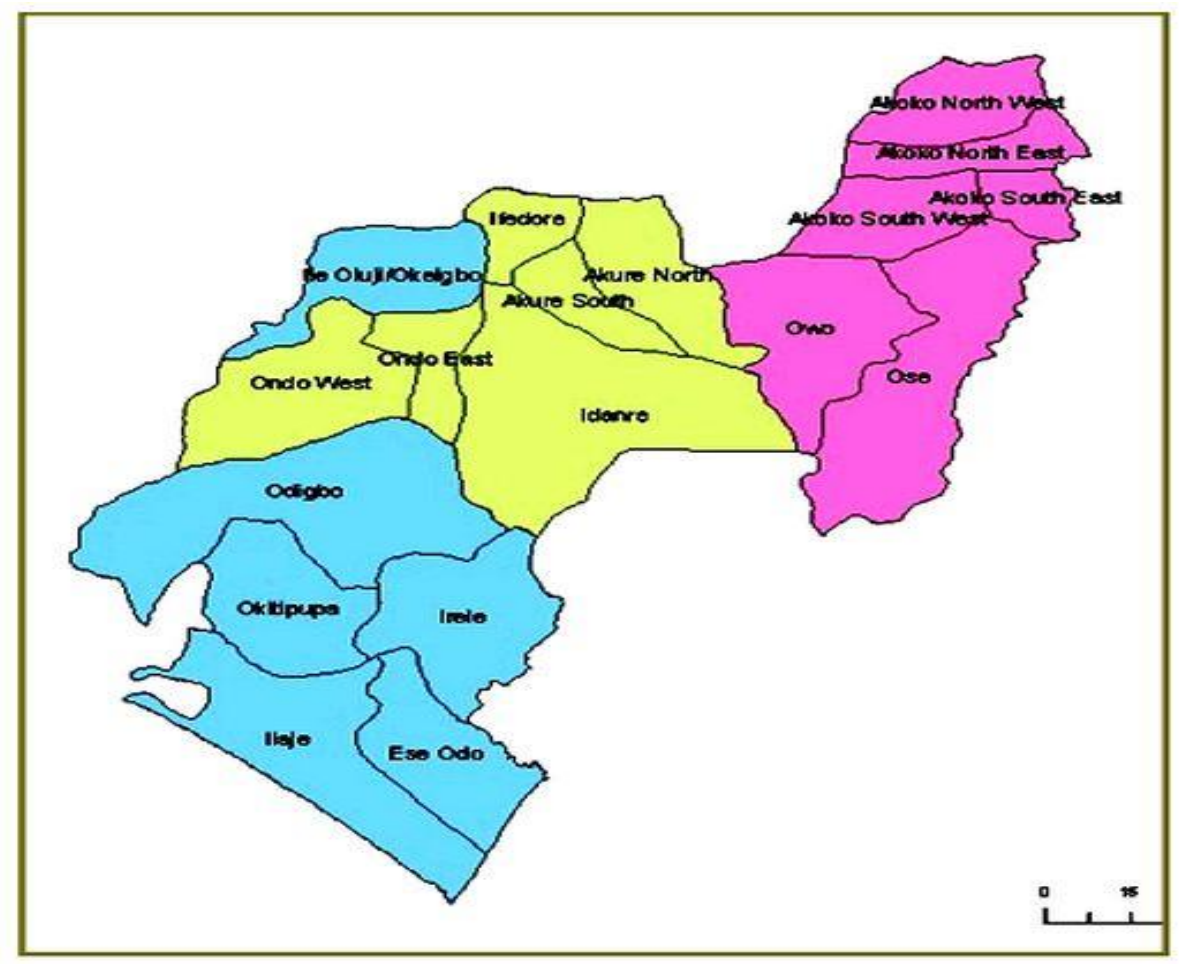

Fig.1.Map of Ondo State showing local government areas 


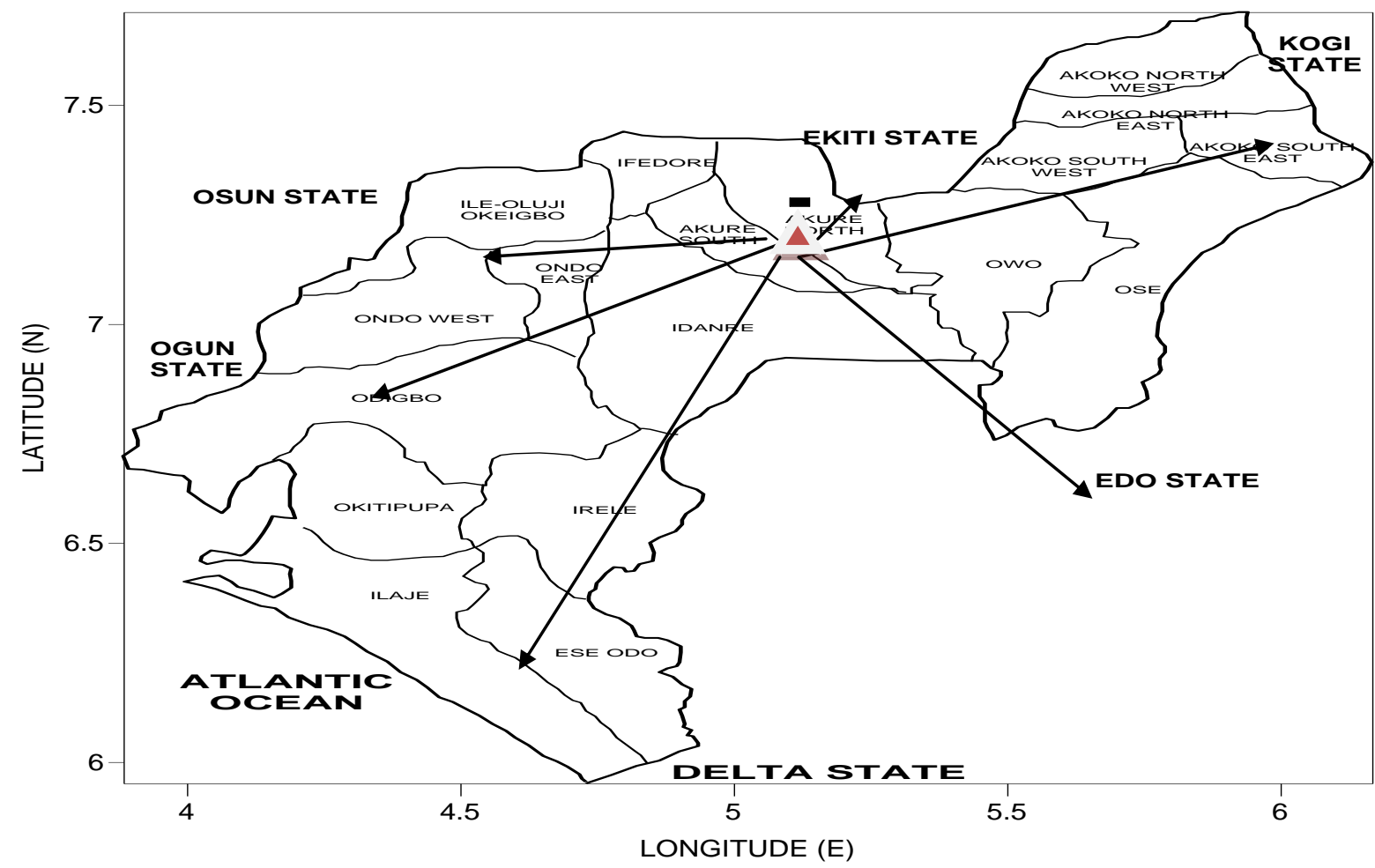

Fig.2.Digital map of Ondo State showing the routes of electric field Strength measurement.

Table 1.Characteristics of the experimental station

\begin{tabular}{cll}
\hline S/No. & Parameter & Height of receiving antenna $(\mathrm{m})$ \\
\hline 1 & Base station's location & Lat. 7.304 ${ }^{0} \mathrm{~N}$, Long. 5.161 ${ }^{0} \mathrm{E}$ \\
2 & Base station's transmitted power $(\mathrm{W})$ & 16,000 \\
3 & Base station's frequency $(\mathrm{MHz})$ & 487.25 \\
4 & Transmitter in use & Harris 40kW UHF Sigma Diamond Drive \\
5 & Height of transmitting mast $(\mathrm{m})$ & 333.0 \\
6 & Height of transmitting antenna $(\mathrm{m})$ & 18.30 \\
7 & Transmitting antenna gain $(\mathrm{dB})$ & 31.70 \\
8 & Height of receiving antenna $(\mathrm{m})$ & 1.80
\end{tabular}

\section{Materials and Methods}

This work is such that requires the physical presence of the research team with the necessary materials and instruments for data collection and recording along all the routes in the study areas. Details of the instrumentation and the methods adopted are presented below.

\subsection{Instrumentation}

A digital field strength meter, Dagatron TM10 (Fig. 3a) was used for the field strength measurement, 
whereas a global positioning system receiver, GPS Map 76 personal navigator (Fig. 3b) was used for the measurement of elevation, geographic coordinates and the line of sight of the various data locations from the base station. A field vehicle was used for the field campaign with the receiving antenna attached. Other accessories used were an I-connector, coaxial cable, a dual dipole receiving antenna and the administrative map of Ondo State for route guide.

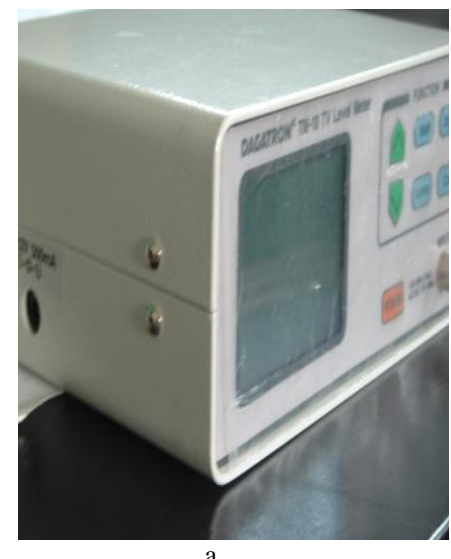

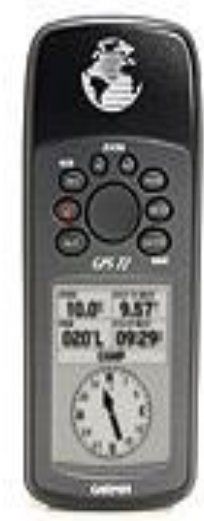

$\mathrm{b}$

Fig.3.a: The Dagatron TM10 Field Strength Meter, b: GARMIN MAP 76, GPS Receiver

\subsection{Electric Field Strength Measurement}

Measurement of electric field strength of the Channel 23, ultrahigh frequency (UHF) Television Station was carried out radially from the base Station along different routes in the State using a digital field strength meter. Detail of the routes categorization is as presented in Table 2. The station's transmitting antenna located at Oritaobele, Akure, was marked and used as the reference point using the GPS receiver for all the routes. The GPS receiver cursor was placed on the base station's location already marked on the GPS waypoint memory. The line of sight from the base station was monitored during the drive. The GPS equally measures the location's longitude, latitude, and the elevation. The Dagatron TM10 field strength meter with the receiving antenna connected to it via a coaxial cable of about $1.2 \mathrm{~m}$ length using an, I-connector was powered for the field strength to be measured. Measurements were carried out at intervals of $5 \mathrm{~km}$ line of sight and in all the towns and villages along the routes, until the signal fades away completely. In summary, the electric field strength values, geographic coordinates, elevation above ground level as well as the line of sight of the various data locations were recorded and collated for necessary analysis. Arrangement was made with the base station's management to ensure transmission parameters were kept constant throughout the period of measurement.

Table 2.Route definition for the field work

\begin{tabular}{clc}
\hline Route & Direction/ Definition & Line of sight LOS $(\mathrm{km})$ \\
\hline A & Transmission base in Akure towards Isua Akoko & $0-85$ \\
B & Transmission base in Akure towards Oke Agbe Akoko & $0-80$ \\
C & Transmission base in Akure towards Igbara Oke/ Owena Osun & $0-20$ \\
D & Transmission base in Akure towards Ikere Ekiti & $0-30$ \\
E & Transmission base in Akure towards Idanre & $0-25$ \\
F & Transmission base in Akure towards Okitipupa/Igbokoda & $0-100$ \\
\hline
\end{tabular}




\section{Results and Discussions}

In any broadcasting system, one of the fundamental tasks is to predict the coverage areas and the path loss due to the interaction of the waves with the environment. Determination of propagation profile or propagation curve is one of the methods to chieve this. Prediction of path loss is an important element of system design in any communication systems especially in radio and television broadcast. (Armoogun, V., et al, 2010) Thus this work is apt at this point due to the novel results it presented, which would be useful for coverage areas prediction and path loss determination of UHF waves in the study areas. Presented below are the results and discussions.

\subsection{Results}

The collated results were categorized according to routes of field strength measurement. Elevation and signal strength values were plotted against distance (LOS) to generate the corresponding propagation profiles/curves for each of the routes.

Tables 3 and 4 present the sample data recorded for routes $\mathrm{A}$ and $\mathrm{F}$ respectively. Fig.4., Fig.6., Fig.8., Fig.10., Fig.12., and Fig.14., present the combined elevation and propagation profiles of the channel, 23 UHF television signal along routes A, B, C, D, E and F respectively. Whereas, Fig.5., Fig.7., Fig.9., Fig.11., Fig. 13., and Fig.15., present the electric field strength propagation profiles along routes A, B, C, D, E and F respectively.

Table 3.Sample Data for Route A

\begin{tabular}{|c|c|c|c|c|c|c|}
\hline \multirow[t]{2}{*}{ S/No. } & \multicolumn{3}{|c|}{ Location/Geographic coordinates } & \multirow{2}{*}{$\begin{array}{l}\text { Line of sight (LOS) from } \\
\text { Base Station }(\mathrm{km})\end{array}$} & \multirow{2}{*}{$\begin{array}{c}\text { Elevation } \\
\text { AGL(m) }\end{array}$} & \multirow{2}{*}{$\begin{array}{c}\text { Signal } \\
\text { Strength } \\
\mathrm{dB} \mu \mathrm{V}\end{array}$} \\
\hline & Town & Lat. $\left({ }^{\circ} \mathrm{N}\right)$ & Long. $\left({ }^{\circ} \mathrm{E}\right)$ & & & \\
\hline 1 & Akure (At Base Station) & 7.304 & 5.161 & 0.00 & 387.1 & 82.50 \\
\hline 2 & Sasa Akure & 7.276 & 5.248 & 10.08 & 340.1 & 40.95 \\
\hline 3 & Ogbese I & 7.273 & 5.340 & 20.00 & 341.9 & 41.70 \\
\hline 4 & Ogbese II & 7.259 & 5.374 & 24.02 & 316.0 & 39.80 \\
\hline 5 & Uso & 7.273 & 5.431 & 30.02 & 327.8 & 40.50 \\
\hline 6 & Owo I & 7.237 & 5.517 & 40.00 & 321.7 & 39.10 \\
\hline 7 & Owo II & 7.211 & 5.558 & 45.00 & 312.0 & 33.1 \\
\hline 8 & Owo III & 7.198 & 5.585 & 48.32 & 353.2 & 46.00 \\
\hline 9 & Owo IV & 7.222 & 5.606 & 50.00 & 289.8 & 23.85 \\
\hline 10 & Oba Akoko & 7.357 & 5.703 & 60.10 & 293.6 & 30.95 \\
\hline 11 & AkungbaAkoko & 7.480 & 5.737 & 66.58 & 363.3 & 32.65 \\
\hline 12 & Oka Akoko I & 7.445 & 5.761 & 68.05 & 357.3 & 41.15 \\
\hline 13 & Oka Akoko II & 7.448 & 5.797 & 72.00 & 569.9 & 60.10 \\
\hline 14 & Oka Akoko III & 7.456 & 5.814 & 74.00 & 551.3 & 33.60 \\
\hline 15 & EpinmiAkoko & 7.454 & 5.860 & 78.97 & 422.4 & 18.80 \\
\hline 16 & IsuaAkoko & 7.454 & 5.911 & 84.43 & 369.8 & 15.65 \\
\hline
\end{tabular}


Table 4. Sample Data for Route F

\begin{tabular}{|c|c|c|c|c|c|c|}
\hline \multirow[t]{2}{*}{ S/No. } & \multicolumn{3}{|c|}{ Location/Geographic coordinates } & \multirow{2}{*}{$\begin{array}{l}\text { Line of sight (LOS) from } \\
\text { Base Station }(\mathrm{km})\end{array}$} & \multirow{2}{*}{$\begin{array}{l}\text { Elevation } \\
\text { AGL(m) }\end{array}$} & \multirow{2}{*}{$\begin{array}{c}\text { Signal } \\
\text { Strength } \\
\mathrm{dB} \mu \mathrm{V}\end{array}$} \\
\hline & Town & Lat. $\left({ }^{\circ} \mathrm{N}\right)$ & Long. $\left({ }^{\circ} \mathrm{E}\right)$ & & & \\
\hline 1 & Akure (Base Station) & 7.304 & 5.161 & 0.00 & 387.1 & 82.50 \\
\hline 2 & Aponmu & 7.233 & 5.106 & 10.00 & 312.3 & 49.90 \\
\hline 3 & Owena Eleshin & 7.192 & 5.012 & 20.61 & 267.2 & 45.15 \\
\hline 4 & Bolorunduro -Ondo I & 7.170 & 4.964 & 26.38 & 298.5 & 44.90 \\
\hline 5 & Oboto & 7.164 & 4.929 & 30.00 & 264.3 & 40.05 \\
\hline 6 & Ondo I & 7.112 & 4.855 & 40.01 & 270.5 & 53.70 \\
\hline 7 & Ondo II & 7.099 & 4.842 & 42.01 & 258.5 & 40.95 \\
\hline 8 & Ondo III & 7.110 & 4.824 & 43.50 & 247.5 & 20.00 \\
\hline 9 & Ondo IV & 7.064 & 4.843 & 44.06 & 263.5 & 40.40 \\
\hline 10 & Bagbe & 6.982 & 4.849 & 49.75 & 242.3 & 38.70 \\
\hline 11 & Asewele & 6.860 & 4.856 & 59.78 & 160.4 & 16.20 \\
\hline 12 & Omifon & 6.833 & 4.860 & 62.00 & 156.9 & 30.65 \\
\hline 13 & Odigbo & 6.781 & 4.873 & 66.26 & 122.0 & 22.85 \\
\hline 14 & Ore I & 6.753 & 4.874 & 69.03 & 92.6 & 15.40 \\
\hline 15 & Ore II & 6.742 & 4.876 & 70.00 & 80.9 & 15.35 \\
\hline 16 & Ode Aye & 6.670 & 4.820 & 80.00 & 37.3 & 15.31 \\
\hline 17 & Okitipupa I & 6.607 & 4.749 & 89.91 & 21.5 & 15.30 \\
\hline 18 & Okitipupa II & 6.545 & 4.747 & 95.99 & 48.0 & 27.90 \\
\hline 19 & Okitipupa III & 6.505 & 4.759 & 99.41 & 50.9 & 16.50 \\
\hline 20 & Gbodigo & 6.486 & 4.786 & 100.00 & 43.6 & 15.00 \\
\hline
\end{tabular}

\subsection{Discussion of Results and Figures}

At the base station, the measured electric field strength value was $82.50 \mathrm{~dB} \mu \mathrm{V}$ which was the highest in the state. This signal level reduces as the line of sight distance from the transmitter (LOS/ $\mathrm{km}$ ) increases in all the routes even though there were exemptions as revealed in this work. Specifically, along route A, Fig. 5., points a, and $\mathbf{b}$ recorded higher values than closer locations to the transmitter due to higher elevation values as shown in Fig. 4. This did not conform to the inverse square law and the mathematical expression as shown in equation (8). This trend was observed in all the routes as depicted in points, $\mathbf{c}, \mathbf{d}, \mathbf{e}, \mathbf{f}$, and $\mathbf{g}$. Others are points $\mathbf{i}, \mathbf{j}, \mathbf{k}, \mathbf{l}$ and $\mathbf{m}$ in the propagation profiles for Fig.5., Fig.7., Fig.9., Fig.11., Fig.13., and Fig.15., respectively. For route F, towards the southern parts, the elevation falls sharply so also the signal strength was abysmally low, as revealed in Fig.14. The propagation profile in Fig.14., clearly reveals the trough in the southern parts which makes it difficult for communities in these areas to receive the direct signal from the channel 23 station. At few points along the route where high elevations were recorded, signal levels were also enhanced. Beyond Bagbe Town (Lat. $6.98^{\circ} \mathrm{N}$, Long $4.85^{\circ} \mathrm{E}$ and Elevation $242.30 \mathrm{~m}$ ) in Ondo West Local Government Area of the state, elevation drops sharply and consequently the signal level drops sharply except at some few points enhanced by 
elevation, such as points $\boldsymbol{m}$ and $\boldsymbol{n}$, highlighted on Fig.15. This work also revealed the elevation pattern of the state across the three major divisions as follows; in the northern parts, the elevation of location is very high, while it is relatively stable in the central. However, the elevation of location in the southern parts of the state was very low. Interestingly, the signal strength variation follows this pattern. Another result worth mentioning is the value of field strength measured $(60.10 \mathrm{~dB} \mu \mathrm{V})$ at Akoko II, a line of sight of $72 \mathrm{~km}$ from base station with an elevation of $569.9 \mathrm{~m}$ along route A, apparently due to the high elevation. Whereas, towards route $\mathrm{F}$, precisely at Ore II, a distance of $70 \mathrm{~km}$ (LOS) with an elevation of $80.9 \mathrm{~m}$, signal strength of $15.35 \mathrm{~dB} \mu \mathrm{V}$ was recorded. This clearly reveals the influence of elevation of location on the received signal strength on UHF band. The interpretation, is that coverage areas on the VHF/UHF band cannot be based wholly on transmitterreceiver distance (the inverse square law), rather other key dependent variables such as the elevation pattern or terrain of the transmitting areas amongst others must be incorporated.

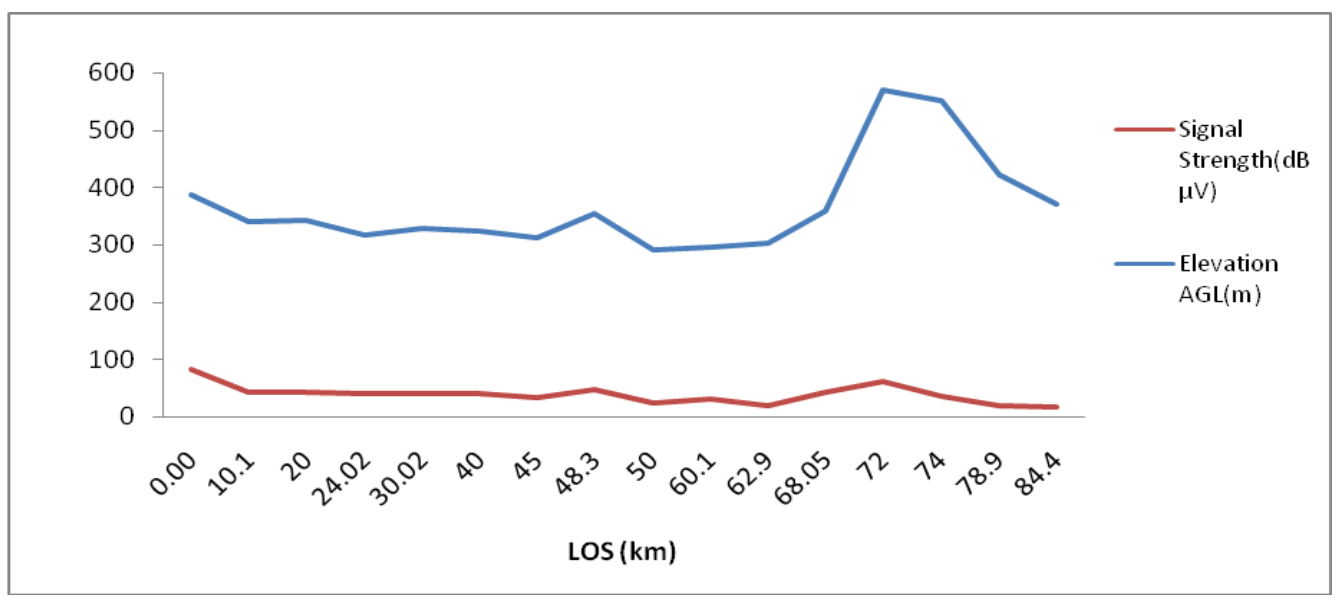

Fig.4.Elevation and propagation profiles from Akure towards Isua Akoko (Route A).

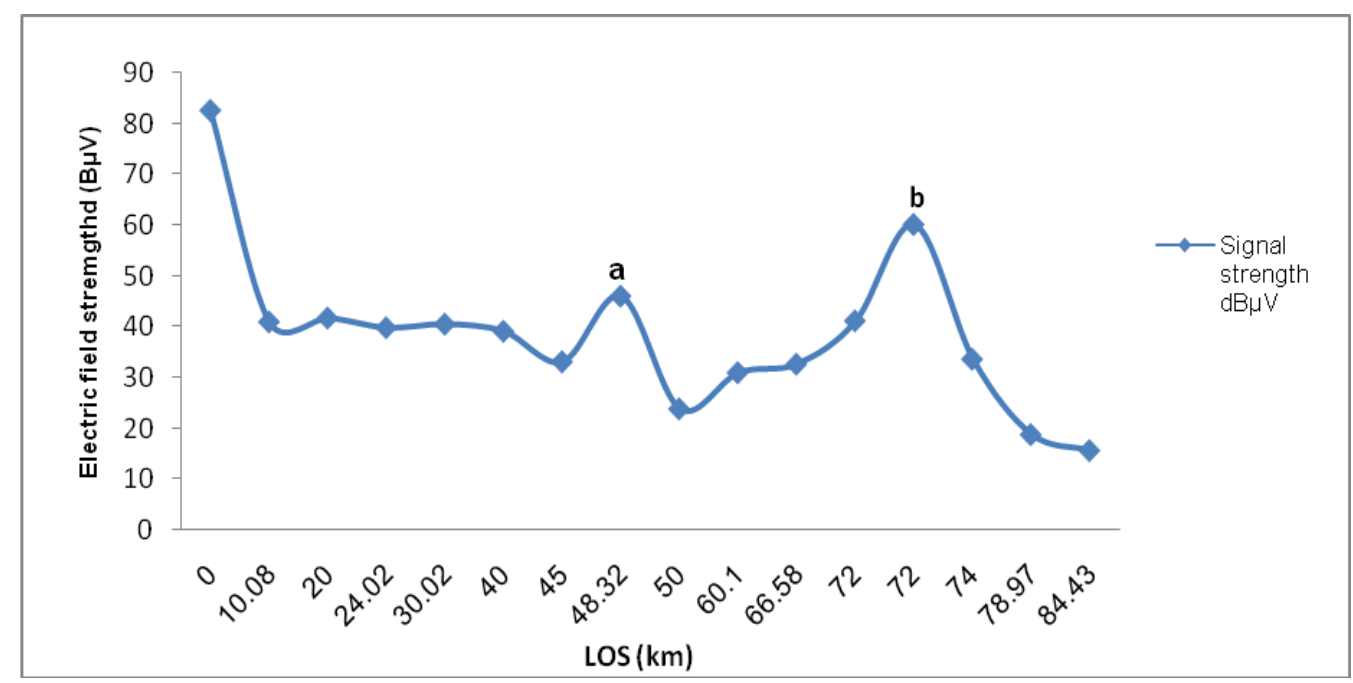

Fig.5.Electric field strength Propagation profile from Akure towards Isua Akoko (Route A) 


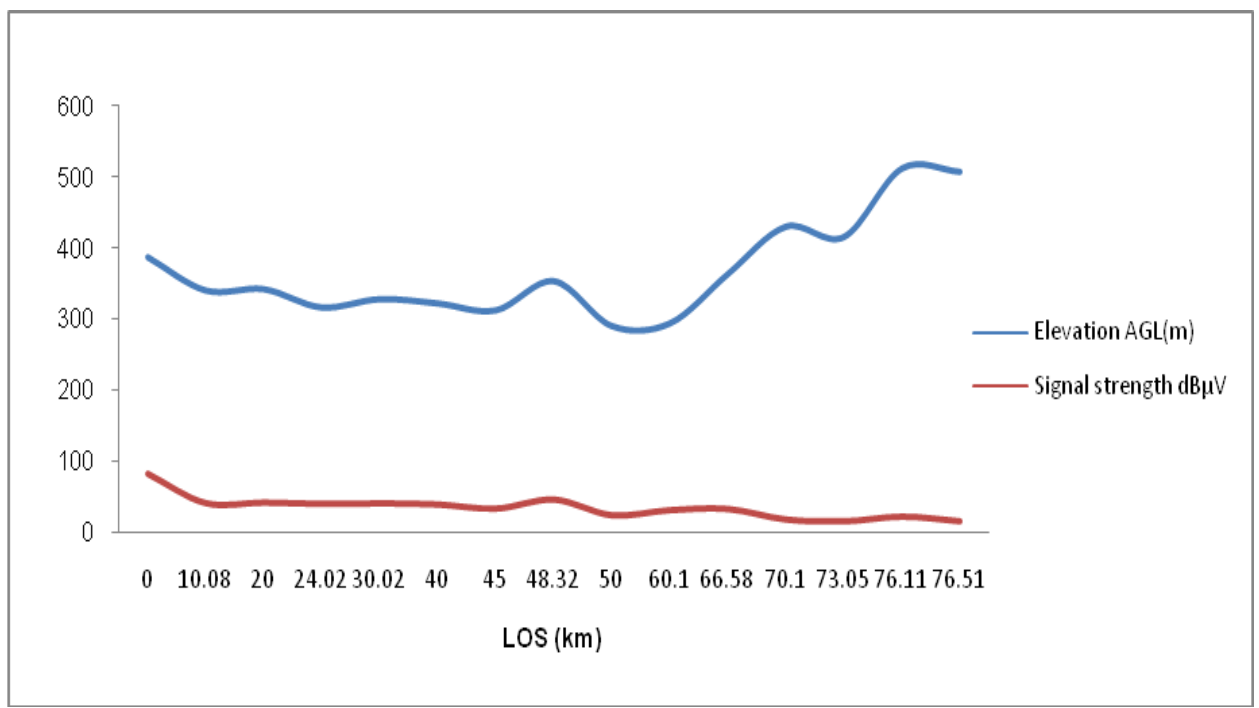

Fig.6.Elevation and Electric field strength Propagation profile from Akure towards Oke Agbe-Akoko (Route B)

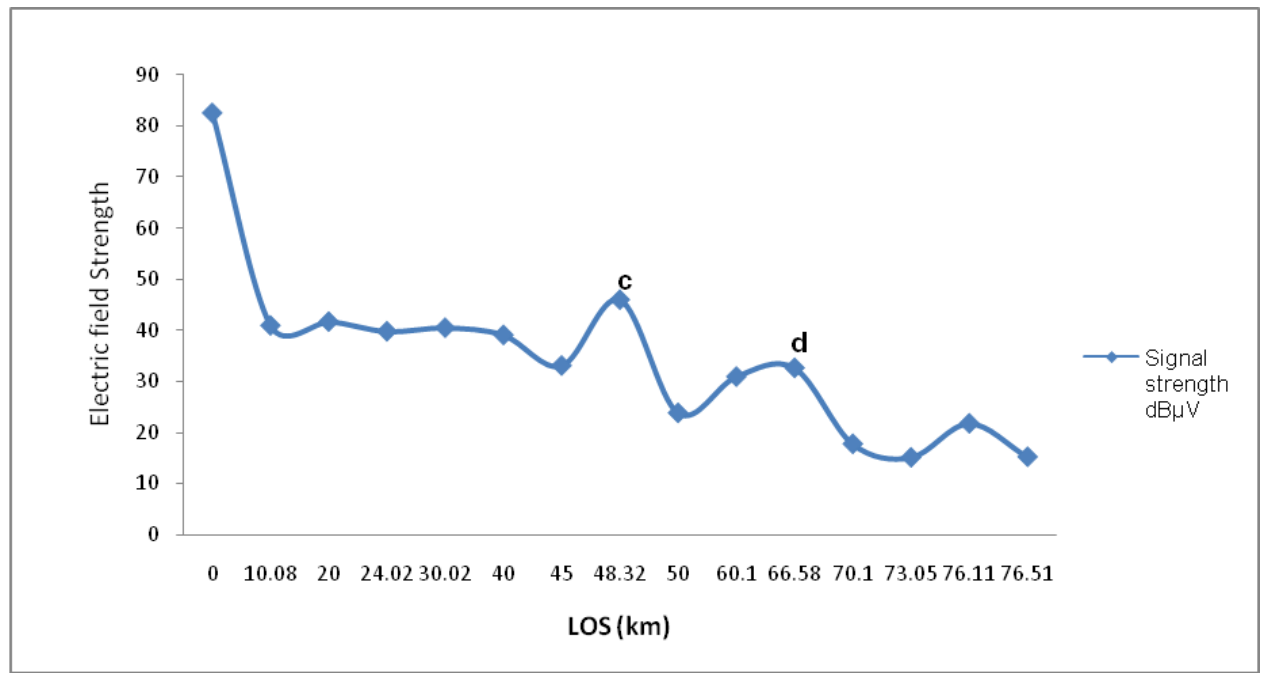

Fig.7.Electric field strength propagation profile from Akure towards OkeAgbe-Akoko (RouteB) 


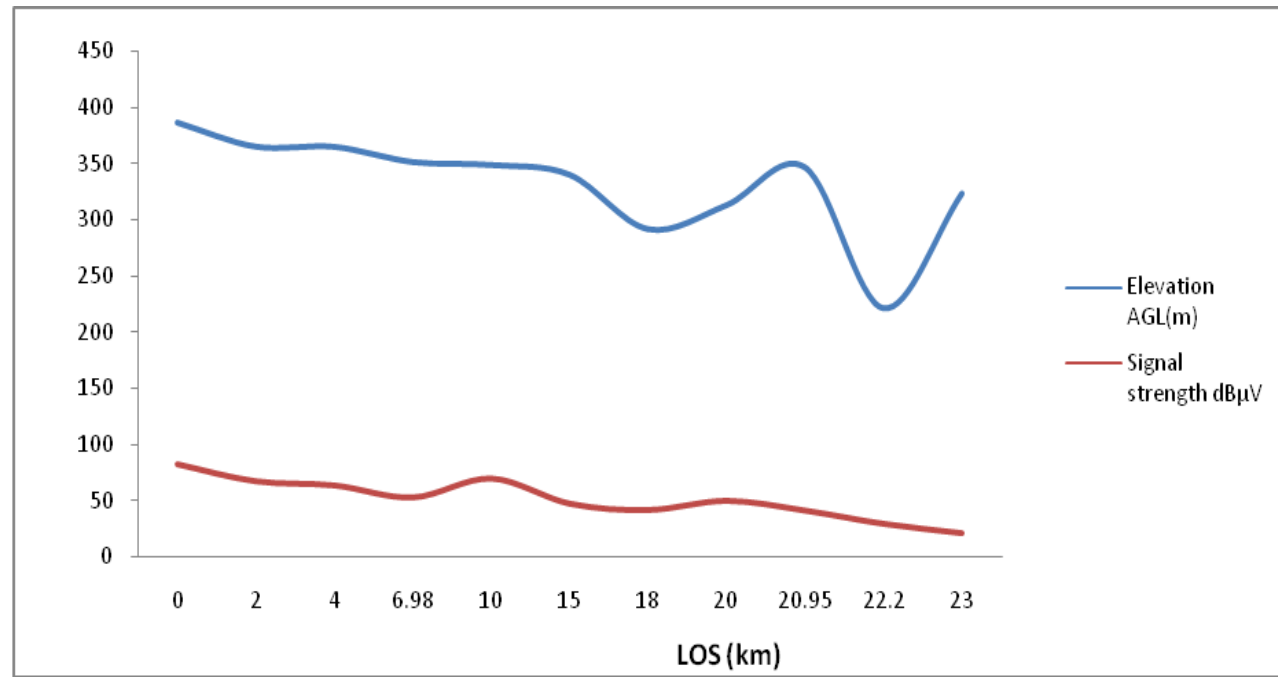

Fig.8.Elevation and Electric field strength Propagation profile from Akure toward Igbara-oke (Route C)

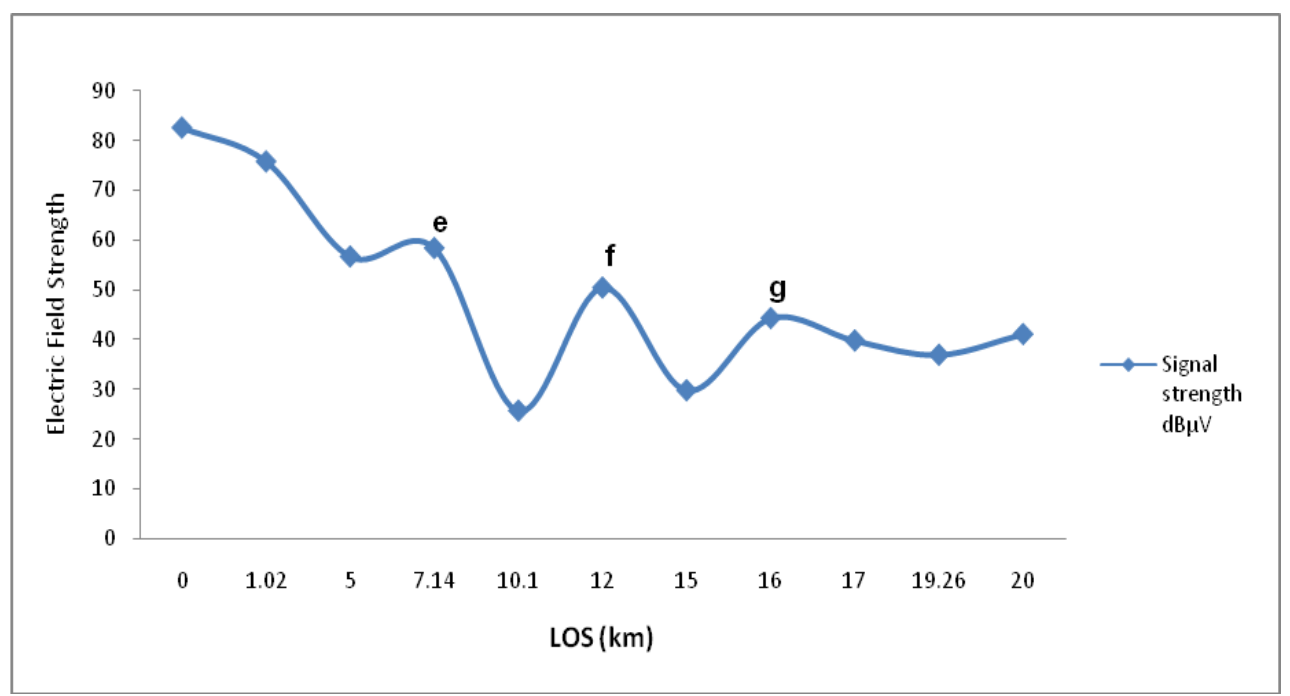

Fig.9.Electric field strength Propagation profile fromAkure towards Igbara-oke (Route C) 


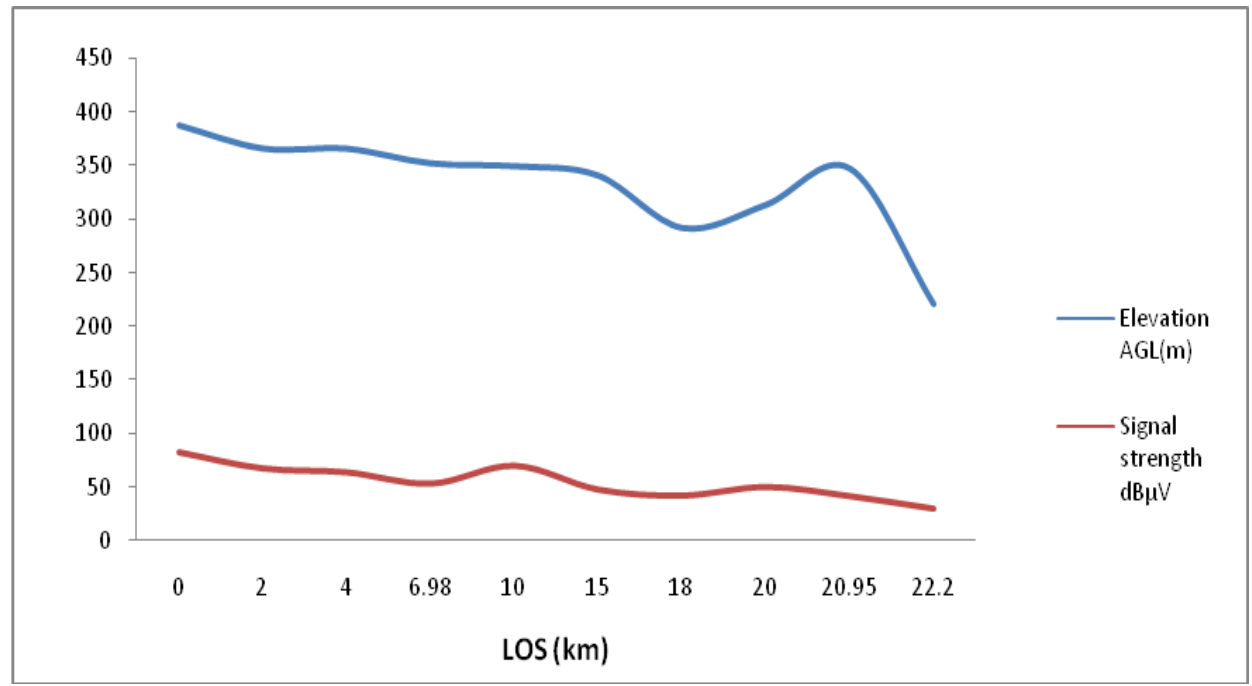

Fig.10.Elevation and Electric field strength Propagation profile from Akure towards Ikere-Ekiti (Route D)

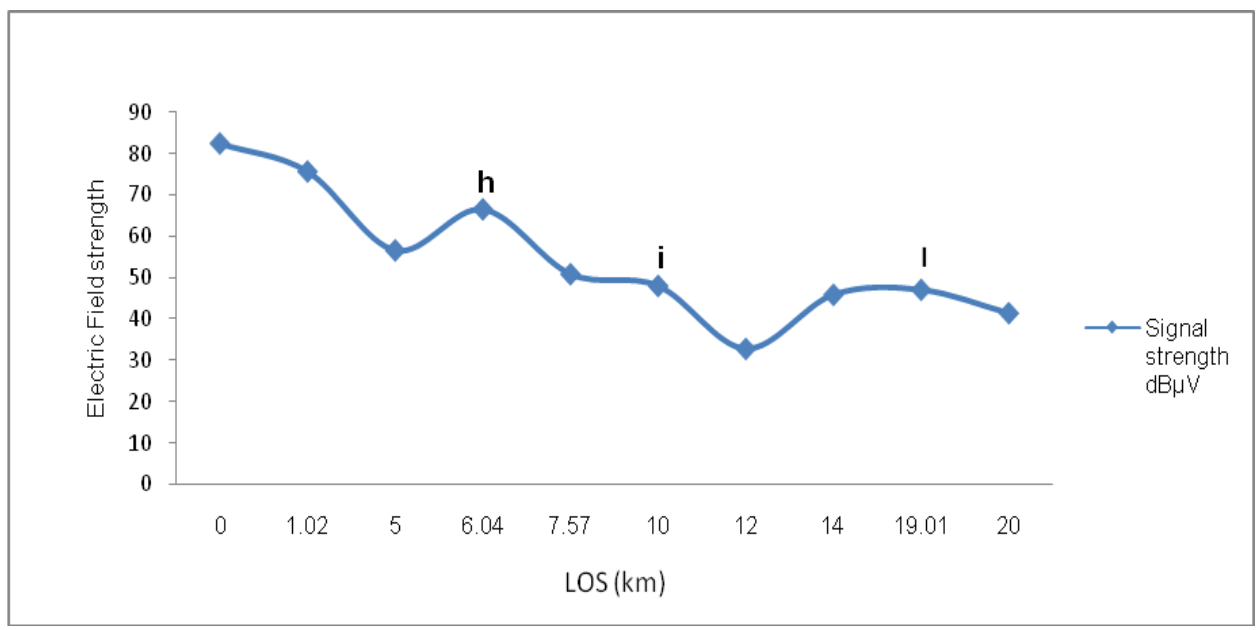

Fig.11.Electric field strength Propagation profile from Akure towards Ikere-Ekiti (Route D) 


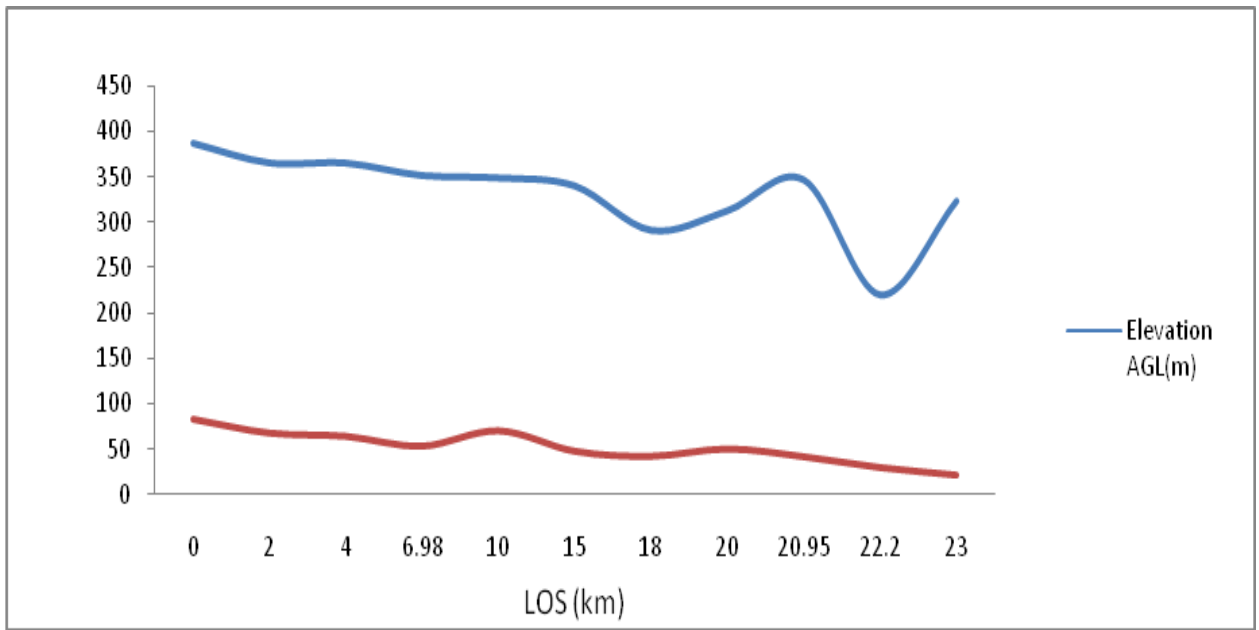

Fig.12.Elevation and Electric field strength Propagation profile from Akure towards Idanre (Route E)

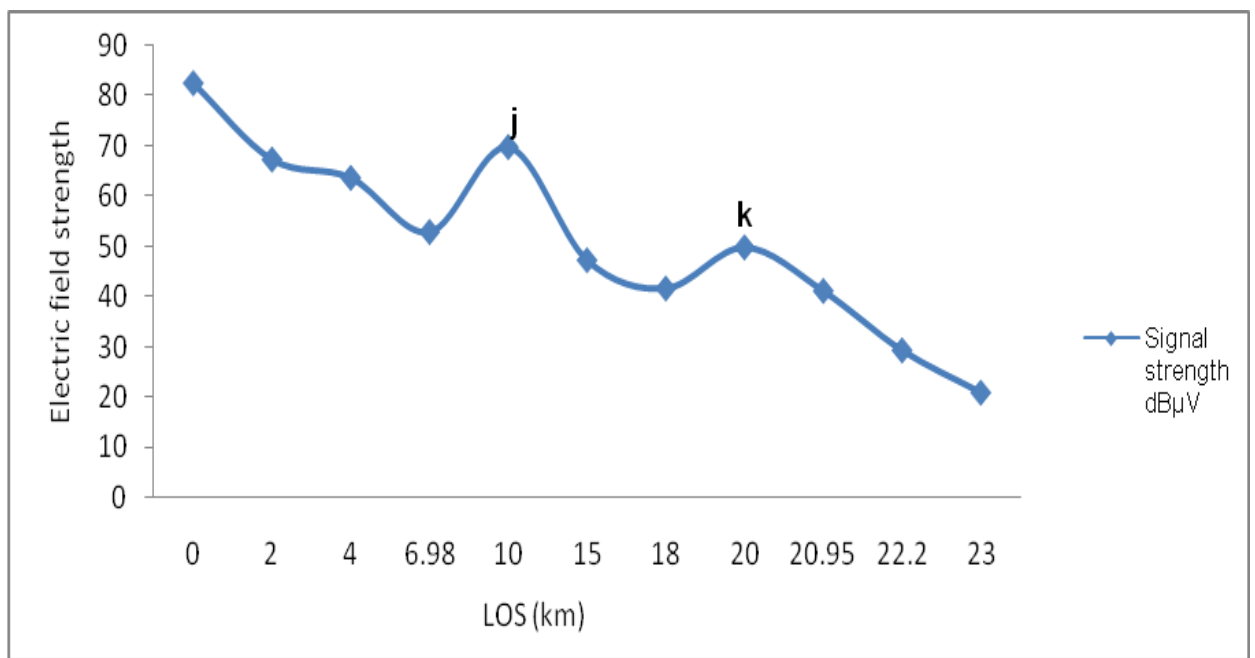

Fig.13.Electric field strength Propagation profile from Akure towards Idanre (Route E) 


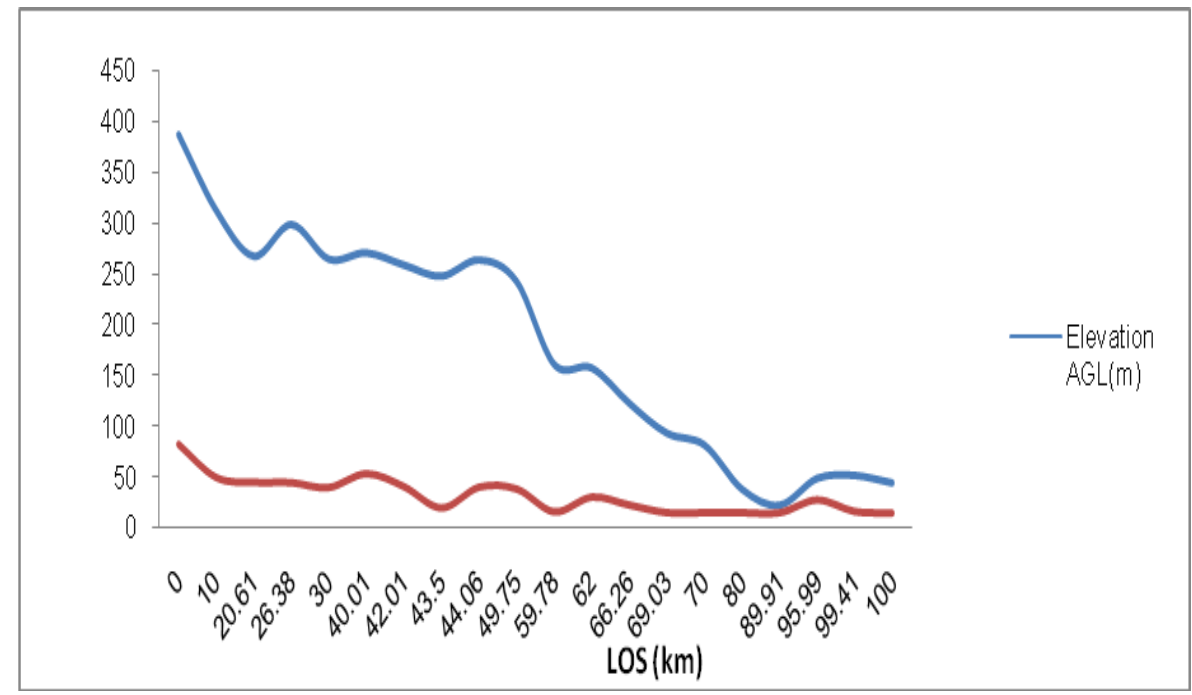

Fig.14.Elevation and Electric field strength Propagation profile from Akure towards Okitipupa/Igbokoda (Route F)

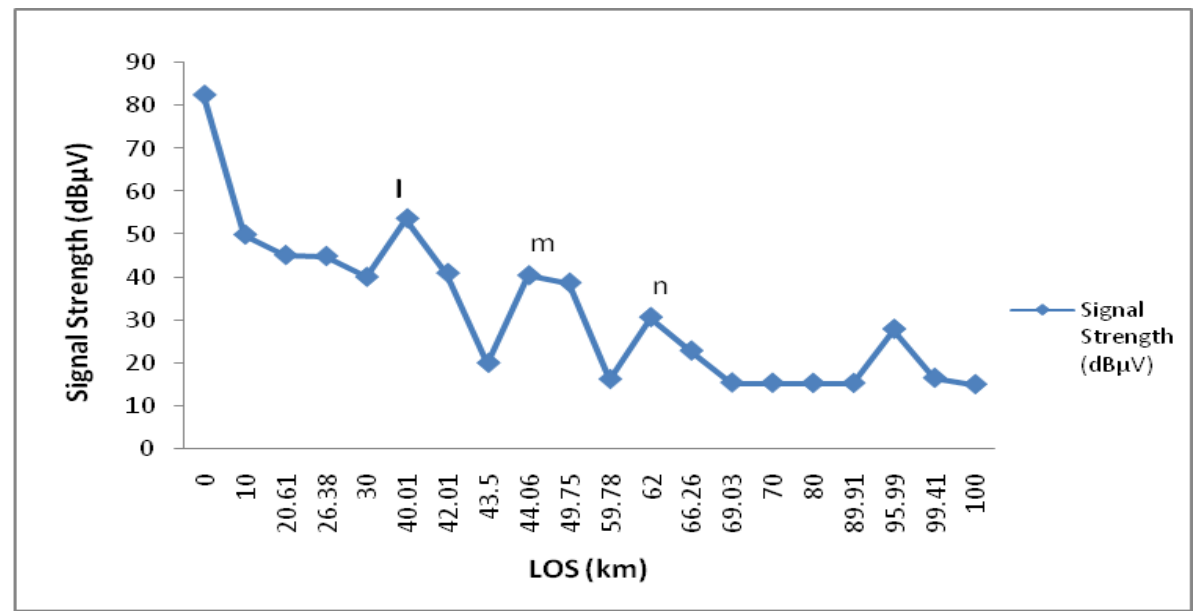

Fig.15.Electric field strength Propagation profile from Akure toward Okitipupa/Igbokoda (Route F)

\section{Conclusions and Recommendations}

\subsection{Conclusions}

In this study, an effective field strength measurement of the channel 23 UHF signal across Ondo State, Nigeria, was conducted as far as road accessibility permits. Other necessary radio communication parameters on the UHF band such as line of sight, elevation and geographic coordinates of the various data points were also determined. This work also produced the elevation and signal strength profiles along various routes of measurements which clearly revealed the effect of elevation on the signal. These findings are very important for radio wave propagation and equipment design on the UHF band by radio scientists and engineers. They are highly necessary for planning now that Nigeria will soon join the World in digital terrestrial transmission on the upper UHF band. The threshold signal level for the station was $20 \mathrm{~dB} \mu \mathrm{V}$ which was recorded up to $50 \mathrm{~km}$ 
line of sight from the transmitter towards the northern part of the state and $42 \mathrm{~km}$ towards the southern parts as determined from the propagation profiles. The implication of this is that, the populace in the northern areas of the state enjoyed better signal quality compared to their counterparts in the southern parts of the state due to high elevation in this region. The propagation profiles for all the routes actually followed the elevation pattern of the study areas; some farther locations recorded higher signal strength compared to closer locations to the transmitter. The implication of this is that on the UHF band, the higher the elevations of receivers from the transmitter the lower the path attenuation and vice versa. The overall result shows that elevation above ground level is a key factor to be considered in propagation modeling for UHF transmission and reception; location of transmitters, transmitting antenna's height, directivity and gain. Others are, transmitter output power, receiving antenna's height and gain in the study areas.

Other findings revealed by this research include:

i. UHF radio signal decreases as distance (line of sigth) from the transmitter increases in the state. The inverse square law was justified but not total because there were exemptions due to higher elevation values recorded at such data locations compared to nearer locations.

ii. Higher values of elevation above ground level were recorded in the northern part of the state compared to the central and southern parts. Towards the southern parts, there was a sharp drop in elevation values consequently the signal strength received at these locations were lowest compared to the northern and central parts with the same distance from the base station.

iii. The elevation values are relatively stable within Ondo Central, consequently signal strength was stable not only for this reason but due to the fact that most locations in the central parts are within $50 \mathrm{~km}$ line of sight from the station because of the linear shape of the State as depicted in the map.

\subsection{Recommendations}

a) The State Government and the management of the broadcast station under study should endeavour to site more booster or repeater stations at a distance of $50 \mathrm{~km}$ line of sight intervals (from the station) towards the southern parts of the state to address the poor reception of signal from the main station in Akure.

b) To be specific, a repeater stations should be sited in Bagbe/Igunshin axis of Ondo West. This is about $50 \mathrm{~km}$ (LOS) from the base station and $50 \mathrm{~km}$ from the only existing booster station in the zone at Okitipupa, with about 450W transmitter power. Beyond this town, elevation of location drops sharply, so also the electric field strength values drop sharply. This proposed station could have a transmitter with output capacity of $2 \mathrm{~kW}$ and should operate maximally. This station, if established will service part of the low signal and fringe areas of Ondo west, Odigbo, Irele, Ondo East, and Idanre LGAs. It will equally make an appreciable signal presence in parts of Ogun, Edo and Osun States. This station (if established) will enhance the socio-economic well being of the people in these areas because they will now have good access to government policies and programmes and all the educative and entertaining programmes of the station.

c) The second proposed station should be in the riverine area of the state, in Igbokoda area. This town is about $150 \mathrm{~km}$ line of sight from the main station in Akure and $50 \mathrm{~km}$ line of sight from the only existing booster station in Okitipupa.

\section{Acknowledgment}

The Management and the Directorate of Engineering Services of the Ondo State Radiovision Corporation (OSRC) Akure, Nigeria, are appreciated for their cooperation during this work and for given us the needed characteristics of the experimental stations. 


\section{References}

[1] Ajayi, G. O.,Owolabi, I. E. CoverageAreas of the $10 \mathrm{~kW}, 702 \mathrm{kHz}$ Medium Wave Transmitter at Minna and Feasibility Studies for full Radio Coverage of Niger State, Technical Report of the Electrical Communication Consultancy Unit (ECCU), Department of Electrical and Electronics Engineering, University of Ife, Nigeria, pp1-3 (1979).

[2] Zeinab, T., Hamide, K., Mesound, B., Mehri, M.,Javad, A.S. Received Signal Strength Estimation in Vehicle-to-Vehicle Communications Using Neural Networks, International Journal of Digital Information and Wireless Communications Vol. 3(3),pp26-30(2013).

[3] Bothias,L. Radio Wave Propagation,McGraw-Hill Inc.New York St. LouisSanFrancisca Montreal Toronto. Pp. (1987).

[4] Kenedy, G., Bernard, D. Electronic Communication System, McGraw-Hill/ Macmillan, Singapore, Pp 8085 (1992).

[5] CCIR Report 239-6, Propagation Statistics required for Broadcasting Service using the frequency range $301000 \mathrm{MHz}$, Recommendation and Report of the ITU-R, Geneva, 1986, In Hall. M. (Ed); Ibid, 256.

[6] Ajewole, M.O., Akinbolati, A., Adediji,A. T.,Ojo, J.S. Precipitation Effect on the Coverage Areas of Terrestrial UHF Television Stations in Ondo State, Nigeria, International Journal of Engineering and Technology, Vol. (4) (9), pp. 524-535(2014).

[7] Akinbolati, A., Ajewole, M.O., Adediji, A. T., Ojo, J. S. Determination and Classification of Coverage Areas of Terrestrial UHF Television Transmitters in Ondo State,Nigeria, International Organization of Scientific Research, Journal of Applied Physics (IOSR-JAP) Vol. (7), (4) PP.16-26 (2015).

[8] Ajewole, M.O., Oyedum, O. D., Adediji, A. T., Moses, A. S.,Eichie, J. O. Spatial Variability of VHF/UHF Electric Field Strength in Niger State, Nigeria, International Journal of Digital Information and Wireless Communications Vol. 3(3), pp26-30(2013).

[9] Ajewole, M.O., Oyedum, O. D., Adediji, A. T., Eichie, J. O., Moses, A.S. Spatial Coverage of FM Radio Transmitters in Niger State, Nigeria, IUP Journal of Telecommunications, Vol. iv, No4, \#70j-2012-11-0101, pp7-12, (2012)

[10] Armoogun, V., Soyjandah, K. M. S., Mohamudally, N., Fugarty, T. Propagation Models and their Applications in Digital Television Broadcast Network Design and Implementation, Trends in Telecommunications Technologies, Christos J Bouras (Ed.), pp166-200 (2010).

[11] Ayekomilogbon, O. T., Famoriji, J. O.,Olasoji,Y. O. Evaluation and Modeling of UHF Radio wave Propagation in a Forested Environment, International Journal of Engineering and Innovative Technology; vol. 2 (12),pp.101-106(2013).

[12] Ayeni, A. A., Faruk,N., Surajudeen-Bakinde, N.T., Okanlawon, R. A., Adediran, Y.A. Spatial Utilization Efficiency Metric for Spectrum Sharing System" International Journal of Digital Information and Wireless Communications Vol. 5(1), pp44-5(2015).

[13] Federal Republic of Nigeria, National Bureau of Statistics, Annual Abstract of Statistics, Abuja, pp. 38-39 (2010).

[14] Samridhi, D., Malhotra, J. Perfomance Evaluation of Channel Codes for High Data Rate Mobile Wireless System, I. J. Wireless and Microwave Technologies (IJWMT) DOI: 10.5815/ijwmt.2015.04.03., pp 24-25, (2015).

[15] Yihuai, Y., Dongya, S., Yonggang, X., Xiangde, L. Matlab Simulink of COST-WI Model, I. J. Wireless and Microwave Technologies (IJWMT) DOI: 10.5815/ijwmt.2012.03.01., pp 1-2, (2012). 


\section{Authors' Profiles}

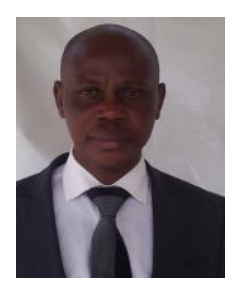

Mr Akinsanmi Akinbolati is a Nigerian communication's Physicist and radio Scientist. He obtains a Bachelor of Technology (B. Tech Honors) in Physics with Electronics in the year 2000, and a Master of Technology (M. Tech) in Communication Physics in 2012, all at the Federal University of Technology, Akure (FUTA) Nigeria. He is currently a Ph.D student of Communication Physics in the same Institution. This author had a good stay in the Broadcast Industry where he had worked as an Engineer for about fourteen years. He has equally obtained a Post Graduate Diploma in Electrical and Electronics Engineering and attended many Academic Conferences and Workshops in addition to Professional Trainings in Broadcast Engineering. Mr Akinbolati has published research work in some reputable local and international Journals and presented papers in Academic Conferences. His areas of research are: Radio wave Propagation and Channel Estimation on FM, VHF, UHF and GSM bands. Others are satellite communication system, GNSS and Atmospheric Influence on Wireless Channels. Presently, he is a Lecturer in the Department of Physics, Federal University Dutsinma, Katsina State, Nigeria. He is a corporate member of the International Union of Radio Science, Nigeria (URSI-NG)

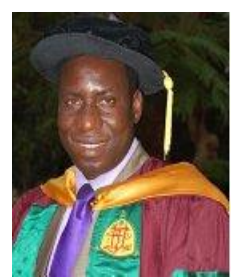

Dr Olaitan Akinsanmi is an Associate Professor of Electrical and Electronic Engineering, and presently the Head of Department, Electrical and Electronics Engineering Federal University Oye-Ekiti, Ekiti State, Nigeria. He obtained a Bachelor of Engineering degree from the University of Ado-Ekiti in 1997, M.Sc and PhD from the famous Ahmadu Bello University, Zaria, Nigeria in 2005 and 2012 respectively. Dr Akinsanmi is a registered Engineer with the Council for The Regulation of Engineering in Nigeria (COREN), Professional Member, Institute of Electrical and Electronics Engineers (IEEE). He is also a corporate member of the Nigerian Society of Engineers (NSE), Associate member, the Nigerian Institute for Biomedical Engineering (NIBE), Fellow of the Nigerian Institute of Natural Resources and Human Development, and a member of the National Association of Educational Managers and Planners (MNAEMP) among others. He is a recipient of Award of The Pillar of Nation Builder in the Academics from The Nigerian Strategic Institute for Natural Resources and Human Development in 2013. He has acquired over eighteen years of research and development with different Universities and other organizations where he has been involved in effective teaching and administrative work. He is a specialist in Computational Electromagnetic, Neural Network Soft Computing in Artificial Intelligence and Reliability of Engineering systems. Dr. Akinsanmi has over thirty-five published journals at both national and international levels.

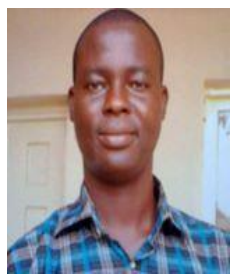

Ekundayo Kehinde Rasaq is currently working at the Department of Physics, Federal University Dutsinma, Katsina State, Nigeria as an Electronics Instructor and Technical Research Associate for Communications \& Technology Research Group. He obtains a Bachelor of Engineering (B. Eng. Honors) in Electrical Engineering in the year 2010, and currently undergoing an M. Sc research thesis in Electrical Power Systems Engineering at the Department of Electrical and Computer Engineering, Ahmadu Bello University, Zaria, Nigeria. His major area of interest is Reliability, Control and Application of FACTS devices and power line communication system. 